\title{
Mudança global do clima e as cidades no Antropoceno: escalas, redes e tecnologias
}

\author{
Global climate change and the cities \\ in the Anthropocene: scales, networks and technologies
}

Marcos Vinícius Isaias Mendes [I]

\begin{abstract}
Resumo
No contexto do Antropoceno, a crise climática revela limitações dos Estados para desenvolver estratégias de mitigação efetivas. Além disso, o aumento da urbanização em nível global trará impactos climáticos consideráveis às cidades. Esses fatores ajudam a explicar o engajamento urbano na política internacional do clima. Entretanto, a literatura brasileira ainda não forneceu uma análise integrada das maneiras como as cidades atuam nessa esfera. Para ajudar a preencher essa lacuna, utilizo o método de revisão sistemática da literatura. Como resultados, proponho três perspectivas integradoras: escalas, redes e tecnologias. Essas três concepções revelam estratégias através das quais as cidades têm atuado na política internacional do clima, a exemplo do ativismo local-global, participação em redes transnacionais e construção de smart cities.
\end{abstract}

Palavras-chave: cidades, mudanças climáticas; Antropoceno; redes; tecnologias.

\begin{abstract}
In the context of the Anthropocene, the climate crisis reveals States' limitations to develop effective mitigation strategies. In addition, the growing levels of urbanization around the world will bring considerable climatic impacts to cities. These factors help to explain urban engagement in the international climate policy. In spite of this, the Brazilian literature has not yet provided an integrated analysis of the ways in which cities operate in this regard. To help fill this gap, I use the method of systematic literature review. As a result, I propose three integrative perspectives: scales, networks and technologies. These three conceptions reveal strategies through which cities have been active in the international climate policy, such as local-global activism, participation in transnational networks, and the construction of smart cities.
\end{abstract}

Keywords: cities; climate change; Anthropocene; networks; technologies. 


\section{Introdução: a cidade global}

A metrópole é uma figura bastante representativa do processo de globalização contemporâneo. Cidades globais incorporam a maioria dos símbolos do desenvolvimento capitalista: elevados níveis de produção, comércio e consumo de bens e serviços avançados; centros de intercâmbio de informações estratégicas para a economia global; fluxos ininterruptos de dados, pessoas, capitais e veículos; arenas de apreciação cultural, produção científica, inovações arquitetônicas e nexo principal das vivências cotidianas de boa parte da população do mundo.

No início da década de 1990, Saskia Sassen escreveu o clássico The global city: New York, London, Tokyo (Sassen, 1991), no qual apresentou uma contribuição original sobre a dinâmica das grandes cidades vis-à-vis o processo de globalização contemporâneo. A economia capitalista encontrava-se numa etapa de formação de hubs financeiros internacionais, pautados por uma lógica de acumulação de serviços avançados. Cidades globais seriam os polos onde se concentravam não apenas os headquarters das maiores corporações do mundo, como também onde se acumulava a força de trabalho especializada.

A tese de Sassen surgia pouco antes da publicação do excepcional livro de Manuel Castells, The rise of the network society (Castells, 1996), no qual um argumento similar se desenharia: "a cidade global é um processo que conecta serviços avançados, centros de produção e mercados numa rede global" (ibid., p. 411). Organizada em torno da sociedade em redes, a cidade informacional seria nada menos que um "processo caracterizado pela dominância estrutural do espaço dos fluxos" de pessoas, capitais e informações (ibid., p. 429). Ambas as obras se tornariam referências fundamentais para a vasta literatura sobre a economia política das cidades que surgiria nas próximas décadas.

É importante ressaltar, no entanto, que, apesar de inovadoras, as contribuições de Sassen e de Castells não foram as primeiras sobre a temática. Em fins dos anos 1960, Jane Jacobs (1969) já havia analisado a dinâmica das cidades, com especial atenção ao mercado de trabalho - que pode desestruturar (como no caso de Detroit/USA após o declínio da indústria automotiva) ou dinamizar (como a indústria financeira fez com Nova York/USA) a economia urbana.

As "hipóteses" sobre o urbano também já haviam inspirado o trabalho de Friedmann (1986), o qual relatara que, ao mesmo tempo que cidades globais são nódulos de acumulação de capital (e poder), disputando posições numa hierarquia mundial, elas também são marcadas pela polarização socioespacial de classes e pela atração descontrolada de migrantes domésticos e internacionais.

Hall (1996) descreveu dois padrões característicos do processo de urbanização contemporâneo.Primeiro: cidades globais competem com cidades "subglobais" (por exemplo, Londres e Paris enfrentariam a concorrência de cidades médias, como Bruxelas, Roma e Genebra, no setor de governo; de Frankfurt e Zurique, no setor de bancário/financeiro;e de Milão, na área de design); segundo: avanços em tecnologias da informação e comunicação (TIC) e nos transportes tornaram as cidades globais cada vez mais dispersas territorialmente (urban sprawl), com a formação de vastas regiões metropolitanas. 
Afora essas concepções econômicas - ou economicistas (Ljungkvist, 2014) - e geográficas, cidades globais também foram analisadas como atores políticos. Castells e Borja (1996) relataram que cidades exercem um protagonismo internacional progressivo no cenário político, em busca de investimentos externos e de mecanismos para a dinamização urbana e o desenvolvimento local. Além disso, Taylor (2000) reconheceu que historicamente as cidades e os Estados intercambiaram padrões de competição (por investimentos e poder) e de mutualismos (já que a conformação de economias nacionais e a prosperidade dos Estados exigem centros urbanos economicamente fortes).

Brenner (1998) desenvolveu um argumento absolutamente original a esse respeito. Segundo esse autor, o Estado passa por um processo de reescalonamento diante da globalização e do surgimento das cidades globais. Estas passam a atuar com função dupla: a) como coordenadas do poder dos Estados, superando o mero papel de correia de transmissão das políticas econômicas nacionais e transformando-se em atores com função estratégica de acumulação, ao passo que aos Estados se relegam funções de controle e de regulação nos níveis regionais e supranacionais; b) como nódulos de acumulação, na transição de uma economia internacional (em que cidades contribuem para o fortalecimento e o crescimento dos Estados) para uma economia global (na quais o crescimento urbano se dissocia do crescimento dos Estados, à medida que a competição entre Estados, cidades e regiões se acelera em escala global).

Esses desenvolvimentos clássicos na literatura sobre cidades globais deram sustentação teórica para explicar o surgimento das redes transnacionais de cidades (Acuto e Rayner, 2016). Com a globalização, cidades e Estados passaram a atuar tanto local quanto globalmente (dinâmicas "glocais"), conformando novas escalas de intervenção política (Brenner, 2009). Ao passo que essas escalas são sensíveis à "geografia das redes", já não é factível afirmar que decisões políticas seguem o caminho tradicional (decisões tomadas em cascata do nível internacional, para o nacional e, então, para o local). 0 que ocorre com a globalização é a conformação de arranjos híbridos de governança, em que questões políticas e econômicas são "criadas, construídas, reguladas e contestadas através e entre escalas e via arranjos híbridos de governança, operando em redes" (Bulkeley, 2005, p. 876).

Nesse ínterim, municípios ao redor do mundo passaram a conformar redes transnacionais, com finalidades que vão desde o intercâmbio de políticas até a cooperação para o enfrentamento de problemas comuns, como é o caso das mudanças climáticas (Betsill e Bulkeley, 2004 e 2007; Andonova, Betsill e Bulkeley, 2009). Alguns exemplos notáveis incluem as redes ICLEI - Local Governments for Sustainability e a C40 - Cities Climate Leadership Group. De fato, segundo Acuto e Rayner (2016), as redes transnacionais de cidades focadas em questões ambientais representam a maioria dessas redes, ou seja, aproximadamente $29 \%$ de um total de 170 catalogadas ao redor do mundo.

Redes de municípios surgiram como arranjos políticos inovadores na busca por soluções para problemas ambientais complexos, numa nova era geológica, sublinhada por intervenções humanas irreversíveis nas dinâmicas do planeta: o Antropoceno. ${ }^{1}$ Provavelmente o termo Antropoceno tenha se tornado notório, 
e seu uso se multiplicado na literatura acadêmica, a partir dos trabalhos de Rockström et al. (2009a e 2009b), Steffen et al. (2011, 2015), e Biermann et al. (2012). Esses autores demonstraram empiricamente que nosso planeta possui nove limites ambientais, dos quais três já foram ultrapassados, atingindo níveis perigosos à humanidade: as mudanças climáticas, o nível de perda da diversidade biológica e o ciclo do nitrogênio (Rockström et al., 2009a e 2009b). Desse total, as mudanças climáticas e a integridade da biosfera (biomas terrestres, aquáticos e marítimos) seriam limites centrais (Steffen et al., 2015). O Antropoceno seria, então, uma heurística apropriada para a conscientização sobre as questões ambientais e para a busca de padrões mais sustentáveis de governança do Sistema Terra (Biermann et al., 2012; Franchini, Viola e Barros-Platiau, 2017).

Apesar da formulação teórica clássica sobre cidades globais e de vários estudos com observações empíricas sobre a atuação de cidades na política internacional do clima, poucos artigos têm trabalhado a intersecção dessas duas literaturas. E o que é mais grave: não foram identificados até agora, em especial na literatura brasileira, textos que detalhem e sistematizem a evolução desses estudos. Sendo assim, neste ensaio, meu objetivo é analisar como a literatura sobre a economia política das cidades globais conecta-se com as pesquisas sobre mudanças climáticas no Antropoceno. 0 método empregado é a revisão sistemática de literatura nacional e internacional sobre o fenômeno, priorizando estudos clássicos ou de grande relevância acadêmica (considerando o número de citações).
O raciocínio desenvolve-se em três momentos. Primeiro, aponto algumas das razões pelas quais as cidades são, ao mesmo tempo, agentes e espaços estratégicos no contexto do Antropoceno. Segundo, analiso como as cidades têm se organizado em redes para enfrentar aquele que talvez seja o maior desafio trazido pelo Antropoceno: a crise climática. Terceiro, analiso como o conceito de smart city associa-se com a questão ambiental, apontando preliminarmente algumas considerações sobre a utilização das TICs (Tecnologias da Informação e Comunicação) no combate à crise climática.

\section{Escalas}

Estatísticas recentes demonstram que o século $X X I$ tem se caracterizado como um século urbano. Estima-se que, em 2050, 68\% da população mundial viverá em cidades (Bouskela et al., 2016). Em 2016, as regiões mais urbanizadas do mundo eram, em ordem decrescente: América do Norte (82\% de população urbana), América Latina e Caribe (80\%) e Europa (70\%). Apesar de África e Ásia ainda serem menos urbanizadas que as regiões anteriores, estima-se que, por volta de 2050, suas populações urbanas representarão, respectivamente, $56 \%$ e $64 \%$ do total (ibid.).

Nesta seção, analiso algumas implicações climáticas derivadas desse cenário de urbanização acelerada. Observo, ainda, como o conceito de Antropoceno vem sendo utilizado nos debates sobre a governança das mudanças climáticas, na perspectiva das diferentes escalas de atuação urbana. 


\section{Governança global do clima no Antropoceno}

Uma temática que tem suscitado intensos debates para a governança global é a instabilidade climática, assim como as implicações pouco otimistas desse fenômeno para as futuras gerações do planeta. Alguns teóricos têm discutido a questão a partir do enfoque de que a humanidade se encontra em uma nova era geológica, chamada Antropoceno. Ou seja, passamos de uma era em que predominava a harmonia entre as dinâmicas ambientais do planeta (Holoceno) para uma era em que a atividade humana tem influenciado e desestabilizado progressivamente tais dinâmicas.

Internacionalmente, Johan Rockström, Will Steffen e Frank Biermann são alguns dos principais autores que têm adotado essa perspectiva. A partir do conceito de limites planetários, os dois primeiros mapearam e dimensionaram a situação ambiental contemporânea do Sistema Terra (Steffen et al., 2011 e 2015), em busca de possibilidades de ação mais concretas no combate aos desequilíbrios ecossistêmicos. Segundo Rockström et al. (2009a e 2009b), haveria nove limites planetários, representados por: 1) mudanças climáticas, 2) acidificação oceânica, 3) diminuição da camada de ozônio estratosférica, 4) ciclos biogeoquímicos do fósforo e do nitrogênio, 5) uso global de água doce, 6) mudanças no uso da terra, 7) perda de diversidade biológica, 8) concentração de aerossol na atmosfera e 9) poluição química. Desse total, a humanidade já haveria transgredido os limites de três: mudanças climáticas, nível de perda de biodiversidade e mudanças no ciclo do nitrogênio.

Em seu framework de limites planetários reformulado, Steffen et al. $(2015$, p. 1) reconhecem a centralidade de dois desses limites: mudanças climáticas e integridade da biosfera (compreendendo biomas terrestres, aquáticos e marinhos), "cada um dos quais com o potencial de mudar significativamente o curso do Sistema Terra, caso sejam substancial e persistentemente transgredidos". A partir desses achados, os autores propõem uma postura que transpasse as "abordagens setoriais de limites ao crescimento visando minimizar externalidades negativas" ${ }^{2}$ (Rockström et al., 2009b, p. 31) em direção a ações mais "efetivas para a gestão planetária", em busca de "um lugar seguro para o desenvolvimento humano" (Steffen et al., 2015, p. 1).

É, em consonância com esse pensamento, que Biermann et al. (2012) entendem que uma mudança incremental nas atitudes da sociedade, em direção a padrões mais sustentáveis, não é suficiente para fomentar as transformações no nível e na velocidade necessários para mitigar os impactos ambientais que têm acarretado tão profundas alterações no planeta. Esses autores entendem que a mudança deve ser estrutural. Para tanto, propõem sete passos para aperfeiçoar a governança do Sistema Terra: 1) são necessárias reformas nas agências e nos programas ambientais da Organização das Nações Unidas (ONU); 2) é preciso fortalecer a integração dos pilares sociais, econômicos e ambientais do desenvolvimento sustentável do nível local para o global; 3) para efetiva governança da sustentabilidade, é preciso fechar as brechas de regulação em nível global; 4) governos devem atribuir maior ênfase às questões ambientais na governança econômica; 5) maior dependência em sistemas de votação por maioria qualificada para acelerar o estabelecimento de normas internacionais; 6 ) instituições 
intergovernamentais fortes, mas submetidas a análises de legitimidade e accountability; e 7) igualdade e justiça como valores centrais do desenvolvimento sustentável em nível global (Biermann et al., 2012, pp. 1306-1307).

No Brasil, a perspectiva do Antropoceno vem sendo adotada por autores como Viola, Franchini e Ribeiro (2012), Viola e Basso (2016), Franchini, Viola e Barros-Platiau (2017), Barros-Platiau et al. (2015) e Inoue (2016), para discutir a governança global do meio ambiente. Em alinhamento com a visão dos teóricos internacionais citados, estes autores apontam que a atual configuração da governança global não é suficiente para solucionar os impasses ambientais. Em um sistema internacional de hegemonia conservadora (Viola, Franchini e Ribeiro, 2012), as nações têm adotado diferentes gradações de compromissos climáticos, do conservadorismo ao reformismo. 0 grande impasse é que boa parte das maiores potências climáticas (países com maior capacidade de influência na política climática global) posiciona-se entre o conservadorismo e o conservadorismo moderado. Além de não haver sinais de reversão desse cenário, ele parece estar se agravando em anos recentes, com uma trajetória de aumento nas emissões de $\mathrm{CO} 2$ por parte considerável dessas potências climáticas (Viola e Basso, 2016, p. 12).

Nesse contexto, Inoue (2016, p. 106) aponta que o entendimento da governança global do clima deve partir da diferenciação entre atores e agentes e as respectivas atividades desempenhadas. A agência "refere-se à capacidade dos atores de prescrever comportamentos e participar substancialmente e/ou estabelecer suas próprias regras relacionadas às interações entre humanos e seu ambiente natural" (Schroeder, 2010, p. 317).

Conforme Schroeder (ibid.), a agência existiria em diferentes "graus", que podem ser sumarizados como segue: a) o ator seria informado de fatos e resultados da política internacional (nenhum grau de agência); b) consultado ou convidado a prover input ou feedback (agência fraca e indireta); c) envolvido como parceiro júnior, com garantias de que visões e preocupações serão refletidas nos resultados (agência forte, mas indireta); d) convidado a colaborar em bases iguais (agência fraca, mas direta); e) empoderado e com autoridade de decisão (agência forte e direta).

A partir da ideia de diferentes graus de agência, Inoue (2016) apresenta um marco analítico para a governança global do clima, que envolveria alguns conceitos-chave.

Arquiteturas de governança: refere-se a um "arcabouço amplo de instituições públicas e privadas, isto é, organizações, regimes e outras formas de princípios, normas, regulações e procedimentos de tomada de decisão que são válidos ou ativos numa determinada área (issue area) da política" (Biermann et al., 2010 apud Inoue, 2016, p. 107). Naturalmente fragmentadas, as arquiteturas de governança global diferenciar-se-iam em termos da miríade de atores envolvidos, do grau de aninhamento institucional (institutional nesting) e da existência de conflitos entre as normas institucionais, podendo ser classificadas em: sinergéticas, cooperativas ou conflitivas.

Redes de governança climática seriam tipos particulares de redes políticas, que reúnem "empresas, sociedade civil e governos em um arranjo, combinando lógicas que normalmente se supõem separadas e 
transcendem a política centrada no Estado e baseada em territórios" (Inoue, 2016, p. 110).

Governança policêntrica estaria associada a múltiplos "centros de decisão formalmente independentes", cada um reunido para gerir recursos comuns (common pool resources) em contextos particulares, em escalas menores que a global. No contexto da governança climática, esse conceito ajudaria a explicar por que "soluções negociadas no nível global, se não foram sustentadas por uma variedade de esforços nacionais, regionais e locais, não devem funcionar" (ibid., p. 112).

\section{As cidades e a questão climática}

Com base nesses apontamentos, é possível situar e (em parte) justificar a emergência de novos atores na governança global do clima, como é o caso emblemático das cidades. Longe de exaustivas, algumas das referências que têm tratado do papel pivotal das cidades nesse sentido são: Acuto (2013a e 2013b), Bulkeley (2005), Bulkeley e Betsill (2005), Bulkeley e Newell (2010), Martins e Ferreira (2011a e 2011b), Inoue (2012) e Aust (2015).

O professor Michele Acuto tem explorado, já há alguns anos, a influência das cidades na governança climática, quer analisando o papel significativo de prefeitos na política internacional quer examinando a conformação de importantes "novos líderes" nesse debate, por exemplo, a rede C40 (Acuto, 2013a, 2013b e 2016).

Acuto (2013a) entende que os prefeitos têm adquirido uma crescente importância na diplomacia transnacional, influenciando a governança global do clima através de cinco mecanismos: 1) construção de regimes para a ação: como é o caso do World Mayors Council on Climate Change, fundado em 2005 logo após a entrada em vigor do protocolo de Kyoto; 2) hibridização da governança: através de mecanismos como as parcerias público-privadas, prefeitos têm conduzido atores públicos, privados e do terceiro setor para cooperação; 3) empreendedorismo diplomático: através de missões e ativismo transnacional, por exemplo por meio da conformação de redes como Mayors for Peace, C40 e Eurocities; 4) mediação normativa: ou seja, crescente capacidade de influência na construção de quadros normativos internacionais; e 5) impacto nas relações internacionais "cotidianas": capacidade de trazer para o nível local, com pragmatismo e maior capacidade de implantação de políticas públicas, questões de grande relevo no sistema internacional.

Outra autora de destaque no estudo da ação climática das cidades é a professora Harriet Bulkeley, do departamento de Geografia da Durham University (UK). Ela tem explorado as imbricações entre os "espaços" e as "escalas" nos rearranjos da governança ambiental, apontando que essas reconfigurações são sensíveis à geografia política das redes (Bulkeley, 2005). Além disso, em outros trabalhos, apontou que a implementação de políticas de proteção climática desafia as hierarquias e as barreiras tradicionais entre o local, o nacional e o global. Ou seja, é necessário adotar uma perspectiva de governança multinivel para entender os desafios e as possibilidades para a construção de cidades sustentáveis (Bulkeley e Betsill, 2005; Betsill e Bulkeley, 2006). Bulkeley e Newell (2010) defenderam, em alinhamento com os trabalhos anteriores da professora, que o debate da governança climática demanda ferramental analítico que 
transcende as abordagens estritamente focadas no Estado, perpassando os diversos atores subnacionais e não governamentais.

0 papel das cidades nesse contexto também já foi discutido por alguns pesquisadores brasileiros. Martins e Ferreira (2011a) avaliaram políticas climáticas em São Paulo e no Rio de Janeiro, encontrando uma alta aderência dessas cidades a redes municipais transnacionais. Em outro trabalho, esses autores alertaram para a grande oportunidade que a governança no nível local representa para a mitigação das mudanças climáticas (Martins e Ferreira, 2011b). Medidas de proteção climática na cidade de São Paulo através de redes municipais também foram estudadas por Setzer (2009) e por Macedo, Setzer e Rei (2016). Além disso, Inoue (2012) analisou como certos municípios da região amazônica brasileira têm participado dos debates e de ações de governança climática.

Destaca-se, também, a recente tese de doutorado de Mauad (2018), que avaliou políticas climáticas em quatro cidades globais da América Latina: São Paulo, Rio de Janeiro, Cidade do México e Buenos Aires. Ao encontrar diferentes gradações de respostas climáticas entre essas metrópoles, sendo a Cidade do México a mais comprometida, e São Paulo a menos eficaz, a autora desafia a generalização de que as cidades estão efetivamente "resolvendo a questão climática". Nesse sentido, apesar de as cidades globais continuarem sendo relevantes no estudo das dinâmicas climáticas, é preciso analisar essas ações de forma mais crítica e pragmática.

\section{Críticas ao Antropoceno e o mito da cidade global: eficácia climática ou marketing?}

A literatura científica ainda está bem dividida entre autores que consideram o Antropoceno uma poderosa concepção, capaz de guiar a sociedade a uma atuação mais efetiva na governança climática (Burke et al., 2016; Hamilton, 2016; Haraway, 2016; Franchini, Viola e Barros-Platiau, 2017) e aqueles que são críticos de tal ideia (Wapner, 2014; Fagan, 2016; Chandler, Cudworth e Hobden, 2017; Bauer e Ellis, 2018).

O Antropoceno pode ser entendido como uma "biopolítica global do carbono", na medida em que traduz a essência de toda a vida e indústria humanas - o átomo de carbono - como uma força central que, ao mesmo tempo que molda/cria a vida (já que o carbono é o principal elemento químico das moléculas orgânicas), também ameaça/destrói o ambiente natural (uma vez que o $\mathrm{CO}_{2}$, gás carbônico, é uma causa central da mudança climática). 0 Antropoceno é, portanto, uma "poderosa força subjetiva que contempla desde as escalas atômicas até as globais" (Hamilton, 2016, p. 1).

Em Planet Politics manifesto, Burke et al. (2016) reconhecem o Antropoceno como uma possibilidade para "formar alianças e fomentar a interdisciplinaridade" tanto no sentido de fortalecer as práticas organizacionais e intelectuais dos cientistas do clima, como para aperfeiçoar as respostas às mudanças climáticas. 0 Antropoceno seria, portanto, um "termo poderoso", que denota não apenas uma época, 
mas um "evento-limite". Uma metáfora que ilustra que o "colapso do sistema" não é um filme de suspense, mas uma construção conceitual que reforça o fato de que uma imensa e irreversível destruição está realmente ocorrendo (Haraway, 2016, pp. 140-141).

Por outro lado, entre os autores críticos do conceito, as opiniões geralmente convergem. 0 termo pode oferecer desafios conceituais e até mesmo obscurecer o debate sobre a dicotomia natureza-sociedade. Como tal, o conceito é muito limitado no que tange às suas contribuições para um quadro crítico no campo da segurança ecológica (Fagan, 2016). A dicotomia homem-natureza, realçada pelo Antropoceno, também representa limitações, uma vez que a proteção ambiental: "não significa criar uma diferenciação entre o bem-estar humano e não humano, mas compreender o caráter coconstitutivo de toda a vida e trabalhar em seu favor" (Wapner, 2014, p. 38). Assim, somente quando tal "política de coconstituição" for plenamente reconhecida por ambientalistas e políticos, o conceito de Antropoceno será verdadeiramente relevante.

A periodização do Antropoceno (Anthropocene divide) também tem sido criticada. A noção de que, apenas após certa data "arbitrária", a atividade humana começou a afetar o meio ambiente poderia ofuscar o "Iongo e antigo processo de alterações ambientais causadas pelo homem", portanto, "obscurecendo, em vez de esclarecendo, um entendimento mais profundo das relações entre homem e natureza" (Bauer e Ellis, 2018, p. 209).

Em resposta direta a Burke et al. (2016), Chandler, Cudworth e Hobden (2017, p. 190) criticam a possibilidade de integração entre Antropoceno e capitalismo contemporâneo: "Burke et al. reproduzem uma estrutura cosmopolita liberal já fracassada e desacreditada por meio da defesa do gerencialismo em vez da transformação; uma abordagem coercitiva top-down do Direito Internacional; e o uso de categorias políticas modernistas abstratas".

Apesar de tais críticas e de outras limitações do conceito, o Antropoceno é uma abordagem recente e crescente entre os cientistas que trabalham com mudanças climáticas e outras questões ambientais. No entanto, um aspecto central dessas críticas precisa ser ressaltado: aquele direcionado à sociedade capitalista contemporânea. Ou seja, o fato de autores como Burke et al. (ibid.) defenderem que o conceito de Antropoceno é compatível com ações climáticas efetivas no atual estágio de "capitalismo selvagem", através de reformas legais e institucionais dentro do próprio sistema.

Essa crítica ecoa em harmonia com autores que questionam o conceito de "cidade global" por sua conotação neoliberal e de mercado. Ou seja, como uma cidade global poderia ser sustentável num contexto capitalista de competição, demandas crescentes por produtividade (e, portanto, aumento do consumo de recursos) e marketização da vida? Como metrópoles completamente inseridas na economia capitalista global poderiam atuar contra as mudanças climáticas?

Alguns autores ilustraram muito bem essas imagens, numa evolução quase linear em relação ao texto seminal de Sassen (1991). Dubai é um caso de destaque no uso de skyscrapers como uma espécie de tecnologia de poder simbólico, aplicando uma estratégia de empreendedorismo urbano na tentativa de tornar-se uma "Nova lorque árabe" (Acuto, 2010, p. 272). Espaços de fluxos constantes, essas metrópoles são fast cities, ${ }^{3}$ 
loci simultâneos de economias vigorosas e transportes modernos, mas também de desigualdades marcadamente neoliberais (Datta e Shaban, 2017). Outro exemplo é o inflado discurso da cidade triunfante, sob o argumento de que as cidades contemporâneas nos tornaram mais ricos, inteligentes, felizes e saudáveis (Glaeser, 2011). Um contraponto evidente ao slogan do "direito à cidade" e da crise urbana neoliberal, difundidos por autores como Harvey (2008) e Maricato (2015 e 2017).

A cidade global seria, assim, marcada por enormes desigualdades socioeconômicas, pela gentrificação dos espaços e pela especulação imobiliária, culminando num direito à cidade apenas a uma minoria privilegiada (Harvey, 2008). Caracterizada pelo alto nível de informalidade no mercado de trabalho (Sassen, 2005), além de problemas de segurança (violência urbana, terrorismo e crimes de ódio racial e étnico), levando a uma variedade de instâncias de militarização da vida urbana (Graham, 2010; Azzi, 2017; Mendes, 2018).

Maricato (2015) critica, por exemplo, a ideia de "cidade como mercadoria", através de estratégias como o "urbanismo do espetáculo" e da indústria de megaeventos. Na visão da autora, os protestos que marcaram o Brasil, em 2013, foram resultado de uma crise urbana, tipificada pela mercantilização do espaço público através do mercado imobiliário e de megaeventos como a Copa do Mundo de 2014 e as Olimpíadas de 2016 (Maricato, 2017).

\section{Redes}

\section{Mudanças climáticas e redes transnacionais de cidades}

Apesar das críticas ao conceito de cidade global anteriormente mencionadas, um crescente número de pesquisadores internacionais e no Brasil têm reconhecido o papel das cidades nos processos de governança global do clima. A conformação dos municípios em redes transnacionais tem sido uma estratégia progressivamente adotada. Essas redes têm sido examinadas através de diferentes métodos e abordagens, tanto objetivando compreender "por que surgiram" (Lee, 2013; Acuto e Rayner, 2016) e "como estudá-las?" (Bulkeley, 2005 e Acuto, 2013b), quanto avaliando casos específicos de cidades nelas inseridas (Mejía-Dugand, Kanda e Hjelm, 2016; Macedo, Setzer e Rei, 2016) e redes expressivas, como ICLEI (Yienger, 2008) e C40 (Davidson e Gleeson, 2015).

Uma abordagem interessante nesse sentido é a associação entre cidades globais e a participação em redes transnacionais de combate às mudanças climáticas. Em um estudo quantitativo, Lee (2013) buscou entender quais fatores estavam associados à participação de cidades nesse tipo de rede. Em seus resultados, encontrou que o "nível de globalização da cidade" influencia muito no engajamento de municípios a essas redes, à medida que fatores como sistema de transporte, fluxo de pessoas e infraestrutura para encontros internacionais possibilitam, às cidades globais, 
maior proatividade nas questões relativas à temática ambiental (ibid., p. 124). Aust (2015) também avaliou a associação entre redes de cidades e mudanças climáticas, concluindo que redes como a C40 desafiam o entendimento do Direito Internacional quanto à relação entre Estados e cidades, sugerindo uma mudança significativa na disciplina, em termos de reconhecimento e/ou contestação do ativismo transnacional das cidades.

Outra perspectiva utilizada para entender essas redes é o uso da teoria ator-rede (Agent-Network Theory), como retratado em Acuto (2013b, p. 838; tradução nossa):

\begin{abstract}
É precisamente pela capacidade de traçar as articulações da sociedade através da configuração (ou falha) de redes que a teoria do ator-rede pode trazer pistas não apenas sobre como a agência de cidades pode emergir na governança global, mas também como redes de cidades tais como a C40 podem "extrapolar" a agência de suas cidades-membro, além de exercerem influência nas relações internacionais similarmente a muitas outras organizações internacionais mais comumente investigadas.
\end{abstract}

Essa possibilidade também já foi apontada em Bouteligier (2012, p. 29), que entende que a configuração em redes pode "aumentar o poder e a influência dos atores políticos, por duas razões: presença global e a vantagem de ser uma rede, e não uma entidade isolada".

Quanto às influências mais diretas dessas redes transnacionais nas políticas públicas municipais, há uma quase predominância de estudos de caso na literatura. Essa abordagem foi ilustrada por Mejía-Dugand, Kand e
Hjelm (2016), que avaliaram a participação das cinco maiores cidades suecas em redes para sustentabilidade. Além da representatividade, foram avaliadas questões como foco, estratégias, procedimentos, desafios e benefícios da participação das cidades nessas redes. Outro estudo de relevo foi conduzido por Oliveira e Doll (2016), que identificaram uma relação positiva entre ações de mitigação a mudanças climáticas e políticas públicas de saúde urbana em duas metrópoles na Índia (Surat e Delhi), através da participação em redes de governança.

Os estudos brasileiros sobre redes de cidades na governança climática, por sua vez, ainda são escassos. Algumas exceções já foram apontadas aqui. Veja-se, por exemplo, o trabaIho de Martins e Ferreira (2011a) que, ao avaliarem o engajamento de São Paulo e Rio de Janeiro em redes transnacionais de municípios, reconheceram que são incipientes as contribuições científicas nessa temática que foquem nas "grandes potências em desenvolvimento", como é o caso do Brasil. Outros estudos continuaram nessa mesma linha, ou seja, focaram na influência das redes em políticas públicas municipais de São Paulo (Setzer, 2009) e do Rio de Janeiro (Mendes e Figueira, 2017), apesar de o segundo não avançar nas políticas climáticas impulsionadas por tais redes.

Outras exceções são o artigo de Inoue (2012), que estudou o engajamento de alguns municípios amazônicos em redes transnacionais; o artigo de Almeida, Silva e Pessoa (2013), que avaliaram o caso de Palmas (Tocantins) no que concerne à integração nesse tipo de rede; e a já referida tese de Mauad (2018), que avaliou as respostas climáticas de cidades como São Paulo e Rio de Janeiro. 


\section{Sobre a eficácia das redes transnacionais de cidades}

Apesar de seu crescente número e legitimidade, alguns estudos identificaram desafios para a eficácia das redes transnacionais de cidades. Ao examinar 13 dessas redes com foco ambiental, Bansard, Pattberg e Widerberg (2017) observaram que a adesão dos municípios geralmente é enviesada para cidades da Europa e da América do Norte, enquanto países do Sul Global estão sub-representados. Além disso, apenas uma minoria dessas redes se compromete com reduções quantificadas das emissões, e as ações de monitoramento são bastante limitadas.

Mejía-Dugand, Kand e Hjelm (2016) afirmaram que é difícil mensurar os benefícios diretos da adesão a essas redes, e não há aparente correlação direta entre a adesão e a implantação de soluções ambientais e climáticas. Além disso, é difícil convencer os políticos a engajar suas cidades nessas redes, dados o esforço e os recursos necessários para manter a filiação. 0 financiamento também é um enorme desafio: "mesmo na $\mathrm{C} 40$, relativamente bem financiada, ${ }^{4}$ quase dois terços (64\%) das ações climáticas são financiadas exclusivamente com os orçamentos ou investimentos das cidades-membro" (Acuto, 2016, p. 613). Portanto, a rede contribui de forma limitada com ações climáticas nos municípios que dela participam.

Partindo dessas limitações, Acuto (ibid.) sugere três estratégias para o aumento da eficácia dessas redes na implantação de soluções para mudanças climáticas. Primeiro, tais redes deveriam aplicar seus recursos financeiros de forma mais estratégica, encorajando ideias inovadoras, como os Urban Living Labs, e explorando formas de financiamento que transcendam às contribuições recebidas das cidades-membro. Segundo, as redes deveriam conectar mais eficazmente diferentes escalas de governança, incluindo cientistas, ONGs, escritórios governamentais locais e nacionais, bancos internacionais e outras redes, a fim de alcançarem maior impacto e influência em políticas públicas climáticas. Terceiro, essas redes deveriam catalisar mais eficazmente interações entre a Ciência e a Política, de modo que cientistas e estudiosos possam utilizá-las como ferramentas de aproximação mais efetiva e adquiram maior influência junto às prefeituras municipais (ou com aqueles que implementam as políticas públicas).

As propostas acima, por um lado, são bastante pertinentes no que tange a maior eficácia dessas redes na influência de políticas públicas climáticas. Por outro lado, elas inevitavelmente recaem no âmbito do gerencialismo liberal e das abordagens políticas top-down, em consonância com o que propuseram Burke et al. (2016), mas não imunes a críticas como as de Chandler, Cudworth e Hobden (2017).

\section{Tecnologias}

\section{Smart cities e sustentabilidade}

Uma estratégia que vem ganhando força na literatura acadêmica e nas práticas políticas é a transformação das cidades em smart cities (Bouskela et al., 2016; Marchetti, Oliveira e Figueira, 2019). De acordo com parte dessa literatura, o objetivo seria tornar os municípios mais sustentáveis e resilientes, ao mesmo 
tempo que prosperassem como cidades modernas e high tech, em alinhamento com as demandas da globalização contemporânea.

De acordo com a rede ICLEI:

Uma smart city incorpora "esperteza" em suas operações, e é guiada pelo objetivo global de tornar-se mais sustentável e resiliente. Ela analisa, monitora e otimiza seus sistemas urbanos, sejam eles físicos (por exemplo, energia, água, resíduos, transporte, emissões) ou sociais (por exemplo, a inclusão social e econômica, governança, participação do cidadão), por meio de mecanismos de feedback e de informações transparentes e inclusivas. Ela se compromete com a aprendizagem contínua e adaptação e, por meio da aplicação do pensamento sistêmico, aspira a melhorar a inclusão, a coesão, a capacidade de resposta, a governança e o desempenho de seus sistemas sociais, econômicos e físicos. (Iclei, 2014, p. 11; tradução nossa)

Esse conceito corresponde à visão de Doran e Daniel (2014) de que o movimento smart city surgiu a partir da ideia de cidades sustentáveis, fazendo melhor uso de TIC para aprimorar serviços de suporte às operações urbanas, tais como transporte, geração de energia e entretenimento. Esses autores propõem um modelo de smart city que integra três componentes: a) econômico, envolvendo a administração pública e os atores econômicos, além de universidades; b) ambiental, abrangendo os recursos naturais e as infraestruturas que os administram; e c) social, envolvendo o cidadão. A cidade inteligente estaria, portanto, no centro de interação desses três vetores, através do uso de TIC nas etapas de coleta, análise e gestão de dados relacionados aos sistemas urbanos (alinhado, portanto, ao controverso conceito de big data).

Ao passo que observam que o uso de big data na gestão pública impactará a divisão e o compartilhamento de atividades, remodelando a governança urbana, Doran e Daniel (ibid.) reconhecem que ainda não está claro como isso se dará. "Como esses novos padrões de governança dependerão das TICs e de tecnologias geoespaciais? Até que nível eles estarão integrados?" (ibid., p. 70). Esses são alguns dos desafios para criação e manutenção de modelos de smart cities sustentáveis.

Chourabi et al. (2012) também propõem um framework para entendimento dessas cidades. Segundo esses autores, há oito fatores críticos em iniciativas de smart cities, a saber: 1) gestão e organização; 2) tecnologia; 3) governança; 4) contexto de política; 5) pessoas e comunidades; 6) economia; 7) infraestrutura construída; e 8) ambiente natural. Esses pilares funcionam como a base de um quadro integrativo, que pode ser utilizado para examinar como os governos locais estão assimilando iniciativas inteligentes, implementando serviços compartilhados e enfrentando os desafios correspondentes.

No entanto, outros autores têm apontado que o termo smart city ainda é vago, e não é utilizado de forma consistente na literatura (Tranos e Gertner, 2012; Mendes, 2017). Com frequência é utilizado de forma intercambiável com wired e digital, por exemplo. Embora o papel das TICs seja a principal característica da smart city discutida na bibliografia científica, outros aspectos também são discutidos na caracterização dessas cidades: a) ênfase no desenvolvimento urbano orientado pelos negócios, atração de empresas e investimentos, muito influenciados pelas noções 
de empreendedorismo e marketing urbano, conformando o que os autores têm chamado de smart economy; b) aumento da participação popular na gestão pública via uso de $e$ -government e o aperfeiçoamento dos serviços públicos, podendo acarretar na melhoria da estrutura, processos e práticas de governo, democratizando o acesso a tais serviços; c) o papel das indústrias criativas no crescimento urbano e a importância de se atrair indivíduos criativos para a cidade, injetando expertise nas empresas e na economia local; d) o papel do capital social no desenvolvimento de smart communities, através de educação tecnológica, conhecimento e inovação (relacionado à open inovation e aos laboratórios de inovação ou Fab Labs); e) à sustentabilidade urbana, envolvendo a interação de sistemas urbanos em três vertentes: física, social e econômica (Tranos e Gertner, 2012).

Porém, a literatura ainda é limitada no sentido de incluir o conceito de smart city numa perspectiva internacional. "A fim de abordar a ausência de uma visão global na agenda política e de pesquisa de smart city, as cidades necessitam estar cientes de sua posição relativa na hierarquia urbana global, e ainda mais ativamente adotar uma agenda local de política externa" (Cappellin apud Tranos e Gertner, 2012, p. 186). Essa "política externa das cidades" seria empiricamente comprovada através das redes transnacionais mencionadas na seção anterior. A participação crescente de formuladores de políticas e prefeitos em fóruns internacionais seria outra evidência disso (Acuto, 2013a).

\section{O papel das TICs no combate às mudanças climáticas: considerações preliminares}

A literatura tem apontado que não basta apenas aplicar TIC na gestão urbana. Para uma cidade ser considerada smart city, é preciso considerar também as dimensões sociais, humana e ambiental (Lange e Waal, 2013; Hollands, 2014). Apesar disso, termo smart city ainda é rotineiramente entendido como a mera aplicação de TIC na gestão urbana. Ahvenniemi et al. (2017) demonstram empiricamente que a literatura acadêmica tem deixado de usar o termo cidade sustentável, à medida que o uso do termo smart city aumenta gradativamente. A partir daí, observam um alto risco de a dimensão ambiental ser negligenciada. Esses autores observam que, apesar de a literatura recente sobre smart city enfatizar também os aspectos sociais, humanos e econômicos, as estruturas de sustentabilidade ambiental ainda são fortemente negligenciadas. Por isso mesmo, propõem o termo sustainable smart city. Esse termo incorporaria o pilar ambiental aos pilares social e econômico, tripé da sustentabilidade.

No entanto, se considerarmos a visão de autores como Franchini, Viola e Barros-Platiau (2017, p. 193), para os quais o próprio termo sustentabilidade é vago e difuso e, portanto, limitado para a conformação de uma Economia Verde de Baixo Carbono (Green Low Carbon Economy, GLCE), o argumento de Ahvenniemi et al. (2017) já nasce ultrapassado. 0 acréscimo da dimensão sustentabilidade ao termo smart city de pouco adiantaria na 
conformação de estratégias de combate às mudanças climáticas.

Para contornar o problema, um argumento que vem sendo utilizado na literatura é a inclusão da temática ambiental e das mudanças climáticas na própria concepção das TICs (Hilty e Aebischer, 2015; Bekaroo, Bokhoree e Pattinson, 2016). Portanto, ao adotar essa possibilidade, o termo smart city - ainda que revertido de uma identidade inevitável com as TICs - poderia gradativamente incorporar também a ideia de proteção ao meio ambiente e o combate às mudanças climáticas.

As TICs incorporariam essas dimensões através de três processos identificados pela literatura especializada. Primeiro, TICs seriam um intermediário na redução das emissões de carbono dos outros setores da economia, ou seja, seriam um low carbon enabler (ibid., p. 1582). Por exemplo, através de tecnologias de virtualização, seria possível conduzir reuniões remotamente, evitando emissões de $\mathrm{CO}_{2}$ com transportes. Da mesma forma, as TICS poderiam ser utilizadas em setores como o de energia, aumentando a eficiência na produção energética ou até mesmo contribuindo para a produção de energias limpas (solar, eólica, das ondas, etc.) (Mazzucato, 2013, p. 164).

Segundo, através de métodos como a avaliação do ciclo de vida (Life-Cycle Assessment), o setor de TIC vem incorporando progressivamente a dimensão ambiental nos projetos de fabricação de hardware e software, incluindo métodos de reciclagem e destinação final de resíduos. Autores como Hilty e Aebischer (2015) denominam esse processo greening in ICT.

Terceiro, com o advento da sociedade da informação em redes (Castells, 1996; Benkler, 2003) e com as tecnologias disruptivas que caracterizam a quarta revolução industrial (Schwab e Davis, 2018), o setor de TIC adquire poder estrutural progressivo na economia política internacional. A smart city seria, por assim dizer, um reflexo desse processo. Dessa forma, alguns autores consideram que as TICs poderão contribuir futuramente para a construção de uma Economia Verde de Baixo Carbono através da descarbonização de outros setores da economia (Hilty e Aebischer, 2015).

\section{Considerações finais}

Através deste ensaio, busquei analisar a relação entre a economia política das cidades globais e a política internacional do clima. A partir do processo de globalização contemporâneo, desenvolveu-se uma rica literatura sobre as cidades globais, alicerçadas nas contribuições de autores como Saskia Sassen e Peter Taylor. Demonstrei que, com o agravamento da crise climática e com as teorizações sobre o Antropoceno, as cidades adquiriram significado estratégico na política ambiental global - particularmente nas políticas climáticas. Isso tanto pelo fato de que as negociações no âmbito dos Estados não trouxeram resultados expressivos (Franchini, Viola e Barros-Platiau, 2017), quanto porque o século XXI tem se caracterizado como um século urbano (Bouskela et al., 2016). Ou seja, as cidades configuram-se simultaneamente como espaços e agentes estratégicos nos processos (políticos, econômicos e sociais) contemporâneos, particularmente no que tange às mudanças climáticas.

Foram apontadas três dimensões de análise sobre a influência das cidades no combate à mudança global do clima: as escalas, as redes e as tecnologias. As escalas dizem respeito 
ao redimensionamento do poder do Estado no contexto de globalização contemporânea processo que Brenner (1998) reconhece como reescalonamento do Estado - tornando iniciativas locais cada vez mais relevantes na política internacional. Nesse sentido, as cidades surgem na literatura como agentes no combate à mudança global do clima, por exemplo, através de teorizações e práticas relativas à governança policêntrica (Ostrom, 2010) e governança multinível (Betsill e Bulkeley, 2006).

As redes estão relacionadas à participação de municípios em arranjos cooperativos globais, como exemplificam os casos do Iclei e da C40, atuantes no campo das mudanças climáticas. Autores como Betsill e Bulkeley (2004), Bulkeley (2005) e Acuto e Rayner (2016) analisaram extensivamente essas estruturas políticas, destacando sua inovação e relevância. No entanto, a eficácia dessas redes tem sido questionada, principalmente pela limitada influência nas políticas públicas municipais (Bansard, Pattberg e Widerberg, 2017; Mauad, 2018).

As tecnologias estão vinculadas à noção de smart city e às possibilidades trazidas por esse conceito para o combate às mudanças climáticas. Ao mesmo tempo que o termo smart city pode minimizar a importância da dimensão ambiental no contexto urbano (Ahvenniemi et al., 2017), ele acentua a importância das TICs na economia política das cidades. Para contornar a percepção de que, numa smart city, apenas as dimensões sociais e econômicas importam, alguns autores sugerem mecanismos através dos quais as TICs possam auxiliar no combate à crise climática (Bekaroo, Bokhoree e Pattinson, 2016). Aqui, destaquei preliminarmente três desses mecanismos: as TICs como low carbon enablers, o uso do Life-Cycle Assessment como método de avaliação dos impactos ambientais das TICs, desde a produção até o descarte dos componentes tecnológicos, e o potencial do setor para influenciar uma mudança estrutural na economia, conformando uma Economia Verde de Baixo Carbono (Franchini, Viola e Barros-Platiau, 2017).

Por fim, cabe salientar alguns pontos importantes para a condução de pesquisas futuras. O potencial das TICs e de outras técnicas e tecnologias modernas para o combate às mudanças climáticas bem como as economias políticas e os interesses latentes nessas iniciativas são pautas que merecem pesquisas mais aprofundadas. Além disso, ainda são necessários estudos empíricos de maior envergadura que analisem a eficácia das redes transnacionais de cidades na conformação de agendas políticas e na efetiva implantação de políticas públicas de mitigação e/ou adaptação às mudanças climáticas. No Brasil ainda são escassos trabalhos teóricos e empíricos que partam da convergência entre a economia política internacional e a política ambiental global. Portanto, esse também é um campo fértil para investigações futuras.

\section{[I] http://orcid.org/0000-0001-7512-8533}

Universidade de Brasília, Instituto de Relações Internacionais. Brasília, DF/Brasil. mvinicius.imendes@gmail.com 


\section{Notas}

(1) Termo cunhado, em 1995, pelo Prêmio Nobel de Química, Paul Crutzen. O Antropoceno é entendido como uma nova época geológica, na qual a atividade humana tem causado profundas e aceleradas transformações na dinâmica ambiental (física, química e biológica) do planeta.

(2) Conforme afirmam Viola, Franchini e Ribeiro (2012), é exatamente esse o tipo de postura constantemente adotado pelas grandes potências em convenções internacionais para o tratamento da questão climática.

(3) Ao passo que reconhecem outras definições existentes na literatura para o termo fast cities, como cidades economicamente pujantes (caracterizadas por inovação, empreendedorismo e crescimento econômico) ou como aquelas com transporte urbano rápido e eficiente, Datta e Shaban (2017) desenvolvem um novo significado para o termo. Na visão desses autores, fast cities são cidades pressionadas a crescer pelas forças do capitalismo neoliberal.

(4) Um dos maiores financiadores da C40 é a Bloomberg Philanthropies.

\section{Referências}

ACUTO, M. (2010). High-rise Dubai urban entrepreneurialism and the technology of symbolic power. Cities, v. 27, pp. 272-284.

(2013a). City leadership in global governance. Global governance: a review of multilateralism and international organizations, v. 19, n. 3, pp. 481-498.

(2013b). The new climate leaders? Review of International Studies, v. 39, n. 4, pp. 835-857.

(2016). Give cities a seat at the top of the table. Nature, v. 528, n. 7580, pp. 429-431.

ACUTO, M. e RAYNER, S. (2016). City networks: breaking gridlocks or forging (new) lock-ins? International Affairs, v. 92, n. 5, pp. 1230-1245.

AHVENNIEMI, H.; HUOVILA, A.; PINTO-SEPPÄ, I. e AIRAKSINEN, M. (2017). What are the differences between sustainable and smart cities? Cities, v. 60, part A, pp. 234-245.

ALMEIDA, L.; SILVA, M. e PESSOA, R. (2013). Participação em redes transnacionais e a formulação de políticas locais em mudanças climáticas: o caso de Palmas. Revista de Administração Pública, v. 47, n. 6, pp. 1429-1449.

ANDONOVA, L; BETSILL, M. e BULKELEY, H. (2009). Transnational climate governance. Global Environmental Politics, v. 9, n. 2, pp. 52-73.

AUST, H. (2015). Shining cities on the hill? The global city, climate change and international law. The European Journal of International Law, v. 26, n. 1, pp. 255-278.

AZZI, V. (2017). Security for show? The militarization of public space in light of the 2016 Rio Olympic Games. Contexto Internacional, v. 39, n. 3, pp. 589-607. 
BANSARD, J.; PATTBERG, P. e WIDERBERG, O. (2017). Cities to the rescue? Assessing the performance of transnational municipal networks in global climategovernance. International Environmental Agreements, v. 17, pp. 229-246.

BARROS-PLATIAU, A. F. et al. (2015). Correndo para o mar no Antropoceno: a complexidade da governança dos oceanos e a estratégia brasileira de gestão dos recursos marinhos. Revista de Direito Internacional, v. 12, n. 1, pp. 149-168.

BAUER, A. e ELLIS, E. (2018). The Antropocene Divide: obscuring understanding of socio-environmental change. Current Anthropology, v. 59, n. 2, pp. 209-226.

BETSILL, M. e BULKELEY, H. (2004). Transnational networks and global environmental governance: the cities for climate protection program. International Studies Quarterly, v. 48, n. 2, pp. 471-493.

(2006). Cities and the multilevel governance of global climate change. Global Governance, v. 12, n. 1, pp. 141-159.

(2007). Looking back and thinking ahead: a decade of cities and climate change research. Local Environment: the international journal of justice and sustainability, v. 12, n. 5, pp. 447-456.

BEKAROO, G.; BOKHOREE, C. e PATTINSON, C. (2016). Impacts of ICT on the natural ecosystem: a grassroot analysis for promoting socio-environmental sustainability. Renewable and Sustainable Energy Reviews, v. 57, pp. 1580-1595.

BENKLER, Y. (2003). Freedom in the commons: towards a political economy of information. Duke Law Journal, v. 52, n. 6, pp. 1245-1276.

BIERMANN, F. et al. (2012). Navigating the Anthropocene: improving Earth system governance. Science, v. 335, n. 6074, pp. 1306-1307.

BOUSKELA, M. et al. (2016). The road towards smart cities: migrating from traditional city management to the smart city. Washington D.C., Inter-American Development Bank.

BOUTELIGIER, S. (2012). Cities, networks, and global environmental governance. Nova York, Routledge.

BRENNER, N. (1998). Global cities, glocal states: global city formation and state territorial restructuring in contemporary Europe. Review of International Political Economy, v. 5, n. 1, pp. 1-37.

(2009). Open questions on state rescaling. Cambridge Journal of Regions, Economy and Society, v. 2, n. 1, pp. 123-139.

BULKELEY, H. (2005). Reconfiguring environmental governance: towards a politics of scales and networks. Political Geography, v. 24, n. 8, pp. 875-902.

BULKELEY, H. e BETSILL, M. (2005). Rethinking sustainable cities: multilevel governance and the 'urban' politics of climate change. Environmental Politics, v. 14, n. 1, pp. 42-63.

BULKELEY, H. e NEWELL, P. (2010). Governing climate change. Londres e Nova York, Routledge (Global Institutions Series).

BURKE, A. et al. (2016). Planet politics: a manifesto from the end of IR. Millenium: Journal of International Studies, pp. 1-25.

CASTELLS, M. (1996). The rise of the network society. Sussex, Blackwell Publishing.

CASTELLS, M. e BORJA, J. (1996). As cidades como atores políticos. Novos Estudos Cebrap, n. 45, pp.152-166. 
CHANDLER, D.; CUDWORTH, E. e HOBDEN, S. (2017). Anthropocene, Capitalocene and Liberal Cosmopolitan IR: a response to Burke et al.'s “Planet Politics”. Millennium: Journal of International Studies, v. 46, n. 2, pp. 190-208.

CHOURABI, H. et al. (2012). Understanding smart cities: an integrative framework. In: 45th HAWAll INTERNATIONAL CONFERENCE ON SYSTEM SCIENCE, pp. 2289-2297.

DATTA, A. e SHABAN, A. (2017). Mega urbanization in the global south: fast cities and new urban utopias of the postcolonial state. Abingdon, UK, Routledge.

DAVIDSON, K. e GLEESON, B. (2015). Interrogating urban climate leadership: toward a political ecology of the C40 network. Global Environmental Politics, v. 15, n. 4, pp. 21-38.

DORAN, M. e DANIEL, S. (2014). Geomatics and smart city: a transversal contribution to the smart city development. Information Policy, v. 19, pp. 57-72.

FAGAN, M. (2016). Security in the Anthropocene: environment, ecology, escape. European Journal of International Relations, v. 23, n. 2, pp. 292-314.

FRANCHINI, M.; VIOLA, E. e BARROS-PLATIAU, A. F. (2017). The challenges of the Anthropocene: from international environmental politics to global governance. Ambiente \& Sociedade, v. 20, n. 3, pp. 177-202.

FRIEDMANN, J. (1986). The world city hypothesis. Development and Change, v. 17, pp. 69-83

GLAESER, E. (2011). Triumph of the city: how our greatest invention makes us richer, smarter, greener, healthier, and happier. Nova York, The Penguin Press.

GRAHAM, S. (2010). Cities under siege: the new military urbanism. Nova York, Verso.

HALL, P. (1996). Globalization and the world cities. United Nations University/Institute of Advanced Studies, n. 12.

HAMILTON, S. (2016). The measure of all things? The Anthropocene as a global biopolitics of carbon. European Journal of International Relations, v. 24, n. 1, pp. 33-57.

HARAWAY, D. (2016). Antropoceno, Capitaloceno, Plantationoceno, Chthuluceno: fazendo parentes. ClimaCom Cultura Científica, v. 3, n. 5, pp. 139-146.

HARVEY, D. (2008). The right to the city. New Left Review, v. 53, pp. 1-16.

HILTY, L. e AEBISCHER, B. (2015). "ICT for Sustainability: An Emerging Research Field”. In: HILTY, L. e AEBISCHER, B. (orgs.). ICT Innovations for Sustainability. Nova York, Springer.

HOLLANDS, R. G. (2014). Critical interventions into the corporate smart city. Cambridge Journal of Regions, Economy and Society, pp. 61-77.

ICLEI (2014). Corporate Report 2014. Disponívelem: http://e-lib.iclei.org/wp-content/uploads/2015/07/ Corporate-Report-2014.pdf. Acesso em: 28 ago 2019.

INOUE, C. (2012). Governance of global climate change in the Brazilian Amazon: the case of Amazonian municipalities of Brazil. Revista Brasileira de Política Internacional, v. 55, pp.170-189.

(2016). Governança global do clima: proposta de um marco analítico em construção. Revista Carta Internacional, v. 11, n. 1, pp. 91-117.

JACOBS, J. (1969). The economy of cities. Nova York/Toronto, Vintage Books Edition. 
LANGE, M. e WAAL, M. (2013). Owning the city: New media and citizen engagement in urban design. First Monday, v. 18, n. 11.

LEE, T. (2013). Global cities and transnational climate change networks. Global Environmental Politics, v. 13, n. 1 , pp. $108-128$.

LJUNGKVIST, K. (2014). The global city 2.0: an international actor beyond economism? Tese de Doutorado. Uppsala, Suécia, Uppsala University

MACEDO, L.; SETZER, J. e REI, F. (2016). Transnational action fostering climate protection in the city of São Paulo and beyond. The Planning Review, v. 52, n. 2, pp. 35-44.

MARCHETTI, D.; OLIVEIRA, R. e FIGUEIRA, A. (2019). Are global north smart city models capable to assess Latin American cities? A model and indicators for a new context. Cities, v. 92, pp. 197-207.

MARICATO, E. (2015). Para entender a crise urbana. CaderNAU-Cadernos do Núcleo de Análises Urbanas, v. 8, n. 1, pp. 11-22.

(2017). The future of global peripheral cities. Latin American Perspectives, v. 44, n. 2, pp.18-37.

MARTINS, R. e FERREIRA, L. (2011a). Climate change action at the city level: tales from two megacities in Brazil. Management of Environmental Quality, v. 22, n. 3, pp. 344-357.

(2011b). Uma revisão crítica sobre cidades e mudança climática: vinho velho em garrafa nova ou um novo paradigma de ação para a governança local? Revista de Administração Pública, v. 45, n. 3, pp. 611-641.

MAUAD, A. C. E. (2018). Latin american global cities responding to climate change? Examinig climate responses from São Paulo, Rio De Janeiro, Mexico City And Buenos Aires from 2005 to 2017. Tese de Doutorado. Brasília, Universidade de Brasília.

MAZZUCATO, M. (2013). The entrepreneurial state: Debunking public vs. private sector myths. Londres, Anthem Press.

MEJÍA-DUGAND, S.; KANDA, W. e HJELM, O. (2016). Analyzing international city networks for sustainability: A study of five major Swedish cities. Journal of Cleaner Production, v. 134, parte A, pp. 61-69.

MENDES, M. V. I. (2017). Competitividade internacional das cidades olímpicas: o caso do Rio de Janeiro. Dissertação de Mestrado. Rio de Janeiro, Universidade Federal do Rio de Janeiro.

(2018). Segurança internacional e o espaço urbano: o papel das redes transnacionais de cidades. In: SEMINÁRIO DA ASSOCIAÇÃO BRASILEIRA DE RELAÇÕES INTERNACIONAIS, n. 4. Anais Eletrônicos, Foz do Iguaçu-PR, pp. 1-33.

MENDES, M. V. I. e FIGUEIRA, A. C. R. (2017). Paradiplomacy and the international competitiveness of cities: the case of Rio de Janeiro. Revista Brasileira de Política Internacional, v. 60, n. 1, pp.1-19.

OLIVEIRA, J. e DOLL, C. (2016). Governance and networks for health co-benefits of climate change mitigation: Lessons from two Indian cities. Environment International, v. 97, n. 1, pp. 146-154.

OSTROM, E. (2010). A polycentric approach for coping with climate change. Background Paper - 2010 World Development Report. Policy Research Working Paper 5095.

ROCKSTRÖM, J. et al. (2009a). A safe operating space for humanity. Nature, v. 461, pp. 472-475.

(2009b). Planetary boundaries: exploring the safe operating space for humanity. Ecology and Society, v. 14, n. 2, art. 32 . 
SASSEN, S. (1991). The global city: New York, London, Tokyo. Princeton/Oxford, Princeton University Press.

(2005). The global city: introducing a concept. Brown Journal of World Affairs, v. 11, n. 2, pp. 27-43.

SCHROEDER, H. (2010). Agency in international climate negotiations: the case of indigenous peoples and avoided deforestation. International Environmental Agreements, v. 10, pp. 317-332.

SCHWAB, K. e DAVIS, N. (2018). Shaping the Fourth Industrial Revolution. Nova York, Penguin Press.

SETZER, J. (2009). Subnational and transnational climate change governance: evidence from the state and city of São Paulo, Brazil. Fifth Urban Research Symposium, Banco Mundial. Disponível em: http://siteresources.worldbank.org/INTURBANDEVELOPMENT/ Resources/336387-1256566800920/6505269-1268260567624/Setzer.pdf. Acesso em: 20 ago 2019.

STEFFEN, W. et al. (2011). The Anthropocene: from global change to planetary stewardship. $A M B I O: A$ Journal of the Human Environment, v. 40, n. 7, pp.739-761.

(2015). Planetary boundaries: guiding human development on a changing planet. Science, v. 347, n. 6223, pp. 1-16.

TAYLOR, P. (2000). World cities and territorial states under conditions of contemporary globalization. Political Geography, v. 10, pp. 5-32.

TRANOS, E. e GERTNER, D. (2012). Smart networked cities? Innovation - The European Journal of Social Science Research, v. 25, n. 2, pp. 175-190.

VIOLA, E. e BASSO, L. (2016). O sistema internacional no Antropoceno. Revista Brasileira de Ciências Sociais, v. 31, n. 2, pp. 1-18.

VIOLA, E.; FRANCHINI, M. e RIBEIRO, T. (2012). Climate governance in an international system under conservative hegemony: the role of major powers. Revista Brasileira de Política Internacional, v. 55 , pp. 9-29.

WAPNER, P. (2014). The changing nature of nature: environmental politics in the Anthropocene. Global Environmental Politics, v. 14, n. 4, pp. 36-54.

YIENGER, J. (2008). Local government lessons on environmental inventories. The Public Manager, v. 37, n. 4 , pp. $10-15$ 
